\title{
PALEOBIOGEOGRAPHY OF CRETACEOUS-EOCENE SOUTHERN HIGH LATITUDE DECAPOD CRUSTACEANS: A TEST FOR GLOBAL CLIMATE MODELING
}

\author{
FELDMANN*, Rodney M., Department of Geology, Kent State University, Kent, OH 44242, \\ U.S.A.; BICE, Karen L. Earth System Science Center, Pennsylvania State University, University \\ Park, PA 16802-2711, U.S.A.
}

Field and museum research on the Cretaceous and Paleogene decapod Crustacea from high latitude, southern hemisphere sites has resulted in development of a data base robust enough to recognize significant biogeographic patterns. Based upon direct examination and verification of all known species from this region, 32 genera arrayed in 20 families of Cretaceous decapods and 35 genera in 21 families of Paleocene and Eocene decapods have been recognized from sites in Antarctica, Argentina, Chile, Australia, and New Zealand. An additional examination of species within 56 genera in 25 families of post-Eocene decapods provides additional control on distributional patterns.

The geographic distribution of these taxa reveals a clear demarcation between groups exhibiting a southern circum-Pacific pattern within the Weddellian Province, and those whose affinities are with low latitude Atlantic and Tethyan groups. The boundary between the two groups lies in the region between the Neuquén and Austral basins, in Argentina, at approximately $45^{\circ} \mathrm{S}$ latitude. The Pacific group largely is comprised of macrurans and podotreme brachyurans whereas the Atlantic-Tethyan assemblage is dominated by heterotreme and thoracotreme brachyurans. Anomuran taxa are found in both distributional groups. This pattern was established at least by the Late Cretaceous and, to some extent, can still be recognized in extant faunas of the region. Because no decapods are known from the circum-Antarctic region today and only one specimen of post-Miocene decapod, currently under study, has been found on the continent, it would appear that the present day biogeographic pattern is a relict of one originally established in the Cretaceous. As many as 11 genera and 15 families of decapods known from Cretaceous occurrences in the region are known from the Cenozoic of the same area. There is no evidence of a significant faunal change, catastrophic or otherwise, at the end of the Cretaceous.

Concomitant with this work, refinement of global climate models, specifically for the middle Eocene, have permitted preparation of high resolution, $2^{\circ} \times 2^{\circ}$, maps detailing conditions of temperature, salinity, horizontal and vertical water movement, and streamlined circulation patterns. Thus, it is now possible to test the relationships between theoretically derived paleoceanographic models and empirically developed patterns of distribution of fossil decapod crustaceans. The correspondence is remarkably good. A cool water mass extended from the Pacific margin of the Antarctic Peninsula into the Atlantic along the east coast of South America northward to about $45^{\circ} \mathrm{S}$. The interface between Atlantic circulation and high latitude water flow was defined on thermal properties of the watermass; no apparent salinity changes or submarine topographic barriers were evident in this region. Eastward flow velocities of less that $1.5 \mathrm{~cm} / \mathrm{sec}$ along the Pacific coastline of Antarctica suggest that larval dispersal across this region would have been relatively slow and that suitable sites for colonization of that coast must have existed to facilitate dispersal from Australia and New Zealand into South America.

Thus, the global circulation pattern modeled for the middle Eocene corresponds very closely to the observed patterns of distribution of fossil decapod crustaceans. The model can be useful in postulating limiting factors to their distribution. Further, pre-Eocene occurrences of fossil decapods support the contention that a similar pattern of circulation may have been operational at least as early as the Late Cretaceous. Although this pattern has been tested on very few taxonomic groups, it is probable that distributional patterns of many benthic invertebrates will exhibit patterns that can be interpreted in the context of this model. 